\title{
Bases Psicofisiológicas de la Gnoseogénesis
}

\section{Psychophysiological Bases of Gnoseogenesis}

\author{
Guy Santibáñez Hidalgo ${ }^{1}$
}

\section{Resumen}

Entendemos por gnoseogénesis el proceso psicológico que conduce a la creación de conocimientos sean estos de carácter empírico o epistemico. Esta génesis es una secuencia producto de una serie de procesos dinámicos que ocurren en la interacción de individuos, de diferentes especies, y los medios con los cuales estos se relacionan o pertenecen.

Las interacciones gnósticas ocurren dentro del proceso evolutivo-histórico. Son parte de la interacción individuo-medio, de la historia o evolución del área envolvente del objeto de las inquisiciones gnósticas y de la historia de las relaciones individuo-objeto de conocimiento.

En el curso de esta interacción el conocimiento acontece gracias a las funciones integrativas del Sistema Neuro-endocrino, considerado por nosotros como el órgano de las regulaciones psicológicas. Funciones integrativas del sistema neuro-endocrino son: la excitabilidad, la plasticidad y la subjetividad.

El conocimiento es una forma de actividad plástica (aprendizajes) basada en configuraciones complejas e integradas de las funciones subjetivas y comportamentales. Ambos aspectos están en íntima relación a través del espacio y del tiempo. La subjetividad es responsable de los aspectos virtuales del conocimiento, el comportamiento es responsable de sus aspectos instrumentales u operativos, y ambos hacen posible la predicción y anticipación de los efectos generados por los procesos gnósticos.

El conocimiento resulta de la interacción entre un individuo y un medio, o de una parte específica del medio. Esta interacción permite la abducción de información obtenida desde el objeto y su codificación por y, en el sistema neuroendocrino. Esta transformación genera una representación subjetiva del objeto de estudio, una imagen virtual, una abstracción del objeto.

El individuo estimula al objeto, mediante manipulaciones de diversa índole, las cuales enriquecen la imagen virtual del objeto con sus reacciones a las manipulaciones. Es decir con las propiedades funcionales del objeto. La interacción gnóstica tiene lugar en condiciones espacio-temporales determinadas dentro de las cuales tienen validez los conocimientos obtenidos.

1 Profesor Titular, Depto. de Psicología, de la Universidad de Chile. e-mail: gsantiba@uchile.cl 
Esta validez está respaldada o basada en la habilidad que adquiere el sujeto de predecir o anticipar las reacciones del objeto ante circunstancias que lo afecten. La prueba más contundente de la validez es la habilidad de crear el objeto, de crear objetos concretos que se ajustan a las anticipaciones predictivas.

Palabras claves: gnoseogénesis, psicología, interacción sujeto-objeto.

\section{Abstract}

Gnoseogenesis is the process that leads to the production of knowledge, either empirical or epistemic.

The genesis of knowledge is a result of a series of dynamic interactions. The best known is the interaction between individuals or groups with the environment to which the gnostic objects belong.

The genesis of knowledge is determined by historical and evolutionary "individualenvironment" interactions: the evolution and history of individual (s)-environment interaction, the history and evolution of the area surrounding the object of the gnostic enquiry, and the history of the individual (s)-object relation of knowledge.

Knowledge is a form of plastic activity (learning), based on a complex structuration of subjective and behavioural functions. These functions are in intimate interaction through time and space, and are generated by the integrative functions of the Neuroendocrine System (NES): excitability, plasticity and subjectivity.

Subjectivity is responsible for the virtuality of the process, behaviour for its operability and both are responsible for prediction and anticipation.

Thus, it is possible to formulate a conceptual descriptive proposition according to which it may be convenient to clarify that knowledge is a psychological process.

So far as knowledge increases, the NES (neuroendocrine system) inhibits the consciousness of the process in order to allow it to become automatic. The change of level in the creation of knowledge implies a parallel course of both forms of function.

Key words: gnoseogenesis, psychology, individual-environment interaction

\section{Introducción}

Entendemos por gnoseogénesis el proceso que conduce a la producción, creación o generación de conocimientos, sean estos empíricos, producto de la actividad práctica, o epistémicos, en cuya elaboración participan criterios que tienden a reglar las condiciones que permiten una relativa seguridad acerca de la validez de los conocimientos. Estos criterios tienen un carácter instrumental, permiten operar sobre el objeto gnóstico, al mismo tiempo que indican como servirse de estos instrumentos. El conocimiento se genera en una condición de necesariedad absoluta: en la interacción actual o potencial, real o virtual, entre quienes crean conocimiento $y$, los fenómenos-objetos en procesamiento gnóstico. Tanto los individuos como los fenómenos-objetos integrados en el proceso de gnoseogénesis pertenecen a un medio. A veces individuos y objetos pertenecen al mismo medio, otras veces a medios diferentes.

Dos cuestiones emergen de esta concepción: una es el significado de "individuo" y 
la otra es, que entendemos por "medio" (Santibáñez-H. y Osorio, 1999).

Habría podido esperarse que hablásemos de "personas", es decir, del Homo sapiens. Justamente no es así. Hay muchos individuos de otras especies que son generadores de conocimientos. Los animales no sólo son capaces de adquirir conocimientos, sino que aún podrían crear cultura (Bonner, 1989; Gomez 1996; Goodall, 1986; FeddersenPetersen, 1987). El conocimiento tiene una larga historia, la cual precede a la historia de la especie humana. Por otro lado, todas, o casi todas las contribuciones científicas acerca de la gnoseogénesis humana han sido modeladas sobre la base de la gnoseogénesis de otras especies (Saavedra, 1999. ).

Nuestra segunda cuestión es lo que entendemos por medio. El concepto de medio implica la idea de algo que rodea, de un elemento en el cual se vive o se mueve una persona, animal o planta, en la condición creada por la extensión espacial o el transcurso del tiempo. El medio es un elemento dinámico que produce situaciones, cambios, variaciones a las cuales los individuos reaccionan. Este concepto describe lo que comúnmente llamamos "medio ambiente".

Una idea ligeramente diferente es lo que C. Bernard (1879) llamó "medio interno" al mundo visceral que está dentro del cuerpo, el cual en vez de rodear, llena. El individuo está en interacción con este medio. Sus variaciones hacen reaccionar al individuo.

Estos dos medios son reales, interactúan con el individuo, por lo tanto generan estímulos. El medio ambiente espera al individuo al nacer, el medio interno nace con el individuo, quien lo trae potencialmente consigo.

Además, hay un tercer medio, que se crea con el desarrollo del individuo. Este medio es construido a través de la experiencia de los individuos. Es también una fuente de estímulos, es dinámico y produce reacciones.
Sin embargo tiene una propiedad particular: es un medio virtual. Es característico para cada individuo, y en una considerable proporción, perceptible para quien lo ha generado. Este medio es el que llamamos "medio subjetivo" (Santibáñez-H., 1990).

Estos tres medios interactúan entre sí. La interacción es mediada por el "Sistema Neuroendocrino", que es el "órgano psicológico" de los individuos (Santibáñez-H. 1986). El órgano que coordina la interacción de los tres medios, que regula los procesos de adaptación-desadaptación y es depositario de la experiencia individual, específicamente de los conocimientos.

La adaptación de los individuos de una especie se produce gracias a la Actividad Integrativa del Sistema Neuroendocrino (Konorski 1968, Santibáñez-H, 1986). Estas son funciones generales de este sistema: La reactividad, la plasticidad y la subjetividad. Estas funciones se integran en la conducta o comportamiento.

\section{La Adaptación y el Objeto de la Psicología}

Al hablar de adaptación hay que considerar al menos dos aspectos : la adaptación de la especie, y la adaptación de los individuos de la especie (Koref-Santibañez-H., 1984). No obstante, debe existir alguna relación entre ambos aspectos del proceso. KorefSantibáñez-H. y Santibáñez-H (1986) propusieron que el "término puede ser usado para indicar el proceso que lleva a la adaptación o para indicar el estado final en el cual la adaptación se ha producido. Ha sido además usado para la adaptación somática y no genética de los individuos, o en sentido genético, para poner en evidencia la reconstrucción del genotipo debido a presiones selectivas durante generaciones". 
Adaptividad es el equipamiento morfológico, fisiológico y psicológico de las especies o de los miembros de ellas, el cual permite competir exitosamente con los miembros de la misma especie o con individuos de otras especies que habitan y utilizan los recursos de un mismo ecosistema, así como para tolerar el ambiente físico de dicho ecosistema. La adecuación adaptativa puede ser debida a componentes particulares del genotipo, a un simple gen o al genotipo en su totalidad.

Esta adaptación ha sido abordada desde tres perspectivas diferentes.

a) La perspectiva genética fue formulada por Waddington (1975) quien distinguió tres tipos de adaptación: La adaptación endógena, claramente de origen hereditario, la adaptación exógena que se modifica por la práctica de determinadas conductas y la adaptación pseudoexógena semejante a la exógena, pero de origen hereditario

b) Marais (1989) abordó el problema desde una perspectiva distinta a la anterior. Analizó el comportamiento. Trabajó varios años conviviendo con babuinos, haciendo cuidadosas descripciones de la conducta de los animales bajo diferentes circunstancias..

Marais sugirió la existencia de tres tipos de memorias como base de la actividad psíquica, que indicarían la existencia de tres estadios en la evolución de ella, y que subtienden modos diferentes de adaptación, a saber :La "memoria filética» responsable de la "actividad instintiva" de los animales, que opera fundamentalmente a través de modificaciones comportamentales no voluntarias, la "memoria individual o causal" que controla la actividad psíquica adquirida por aprendizaje, y la "memoria mixta" que opera conjuntamente con la memoria filética y con la "memoria individual o causal". c) Pavlov $(1904,1927,1953)$ y Konorski (1967, p.7), han considerado el origen de las reacciones efectoras de los organismos, concretamente "el comportamiento». Los comportamientos específicos fueron designados por Pavlov como reflejos "incondicionados", que según Konorski son productos de la "reactividad »del tejido nervioso. Los comportamientos individuales fueron designados por Pavlov como "reflejos condicionados», los cuales según Konorski son productos de la actividad "plástica" del Sistema Neuroen-docrino. Estas son reacciones propias de los individuos. Además existen comportamientos que incluyen ambas categorías, las reacciones mixtas.

Ahora bien, la adaptación exógena de Waddington debe necesariamente corresponder a la dotación psíquica (subjetivo-efectora) de los individuos de diferentes especies, en la cual la adquisición de conocimientos, procesos exquisitamente psicológicos, juega un papel importante. Desde este punto de vista, la adaptación exógena incluye no solamente los procesos efectores, sino también los procesos de anticipación, como fue sugerido por Anojin (1962). Si recordamos la génesis de un reflejo condicionado, se observa que la respuesta incondicionada se liga a un estímulo que antecede al estímulo desencadenante de la reacción incondicionada. Este fenómeno de anticipación puede tener una expresión virtual, es decir, puede adoptar la forma de una representación anticipatoria virtual de la realidad. De tal manera la reacción puede empezar o producirse en el sujeto antes de verse enfrentado a la situación correspondiente al refuerzo.

Al integrar estas contribuciones provenientes de las mencionadas áreas de la investigación científica, podemos sugerir que la adaptación se produce al menos de tres 
maneras : Las funciones reactivas, filéticas, heredadas originan la adaptación endógena. Las funciones plásticas, individuales, aprendidas, originan la adaptación exógena. Las funciones plástico reactivas, heredadas o parcialmente adquiridas, originan la adaptación pseudoexógena.

Aunque esta última manera parezca una función totalmente irreal, puede ser identificada con la inhibición de una respuesta incondicionada, como sucede con la inhibición de la respuesta de enfoque audiovisual (Santibáñez-H \& Siegmund 1977), o la inhibición de la reacción de sobresalto, ambas obtenidas por la repetición de los estímulos que las desencadenan. Este fenómeno es denominado inhibición de un reflejo incondicionado o habituación.

La relación entre la Psicología y la adaptación es muy estrecha. El objeto de la Psicología (Santibañez-H., y Osorio 1998) a nivel macroscópico es el estudio de la diada "adaptación-desadaptación». Señalemos que la Evolución es al mismo tiempo una constante supervivencia de especies que se adaptan, pero que al mismo tiempo es un cementario de las que no tuvieron las habilidades adaptativas exigidas por el medio ambiente. Siendo la Psicología una ciencia ecológica, su campo de acción es el estudio tanto de la interacción individuo-medio adaptativa, como la interacción desadaptativa. Hay procesos psicológicos tanto bajo una condición de distrés como de eustrés (Chananaschwili, 1984).Desde una perspectiva microscópica el objeto de la Psicología es el momento en el cual un suceso ambiental se convierte en un evento individual o intracorporal, o a la inversa, un elemento que emerge del individuo se transforma en una reacción que opera sobre el ambiente.

Tengamos presente que el ser vivo es un estadio particular de la evolución de la materia-energía donde se integran varios nive- les evolutivos de esta materia-energía. No es una superposición de ellos.

Esta cuestión es importante, pues se habla de la "ayuda" que la Biología presta a la Psicología. Tal vez refiriéndose a los músculos, a las vísceras o al Sistema Neuroendocrino. Sin embargo, hay que tener presente que el medio interno (visceral) es completamente dependiente del medio externo para mantener al "viviente en vida", y que esta dependencia significa que no hay vida sin la adaptación del individuo al medio externo, por lo tanto, sin interacción individuo-medio.

Se podría también decir que la Psicología "ayuda" a la Biología en los estudios de Genética de la conducta. No es el caso de pensar que una ciencia "ayuda" a otra, sino que es necesario entender que la Naturaleza es siempre sintética. Ella no es responsable que se la haya parcelado arbitrariamente en compartimentos gnósticos. Esta convergencia sugiere la necesidad de pasar de ciencias parcelarias, analíticas a un enfoque interactivo, interaccional del trabajo científico que realmente refleje el movimiento, el cambio y la interacción de lo existente.

Tal vez sea necesario proponer una distinción entre "lo viviente" y "lo biológico". La concepción histórica de "lo biológico" es una abstracción de "lo viviente". Lo viviente envuelve todas las propiedades funcionales, todos los cambios energéticos de la materia. Esto no permite abstraer lo psíquico de lo biológico, ni lo biológico de lo químico, ni lo químico de lo físico. Salvo en un tratamiento abstractivo-analítico del problema. No es aceptable abducir lo subjetivo comportamental del microcosmo que es un ser viviente. Tampoco es posible abstraer el medio en que este individuo vive de su ser como individuo. Desde este punto de vista el Sistema Neuroendocrino es básicamente un órgano psicológico, al considerar no su 
anatomía sino sus funciones. Esta pertenencia es multifacética, íntima, unitaria, gestáltica. Ella es la que permite integrar en el procesamiento que el "ser viviente" hace de la información proveniente de la interacción individuo-medio. El Sistema Neuroendocrino coordina la adaptación, debe necesariamente ser también considerado un órgano psicológico (Santibañez-H., 1986; Santibañez-H., y Osorio 1999). Esto por varias razones:

- En la evolución, el Sistema Neuroendocrino se desarrolla por la necesidad adaptativa de los organismos, es decir, por funciones emergentes que "crean" un órgano adecuado.

- El Sistema Neuroendocrino o sus partes integrantes no alcanza su madurez anatomo-funcional si no cumplen sus funciones adaptativas desde determinado momento del desarrollo (período crítico). La deprivación sensorial luminosa, por ejemplo, puede producir hasta degeneración retinal y muchos déficits de diversos tipos (Gana, Hirsch y Tiewan, 1972; Zernicki 1991, 1993).

- El entrenamiento favorece incluso la formación de sinapsis en los sistemas neuronales envueltos en esa actividad, acorta el tiempo de reacción y perfecciona las respuestas

Popper y Eccles (1971) también consideran al Sistema Nervioso como un órgano que cumple funciones psicológicas, pero por razones diferentes a las expuestas aquí.

No es aceptable reducir los fenómenos psicológicos a funciones biológicas. Hay que tener presente que lo viviente es más que lo biológico. Este es un error análogo a proponer una reducción de lo viviente al nivel físico o al nivel químico. La evolución integra niveles, pero no excluye niveles.

\section{Adaptación y Conocimiento}

Una de las funciones adaptativas más importantes es el conocimiento.

Entendemos por conocimiento la propiedad de un hecho psíquico determinado, que permite a un individuo o a un grupo de ellos, introducir modificaciones intencionales concretas en el medio externo, en el medio interno, en el medio subjetivo, o en la propia actividad psíquica. En otros términos, puede decirse que alguien conoce algo, cuando tiene el control de ese algo, la posibilidad de modificarlo intencionalmente, la posibilidad de crearlo o fabricarlo. El conocimiento, como cada fenómeno psíquico es un proceso objetivo de interacción entre individuo y medio. Esta propiedad implica necesariamente la habilidad de quien conoce de reflejar subjetivamente, con un grado determinado de precisión, el objeto del conocimiento, y de este modo poder operar sobre él, de una manera eficiente y predictiva.

Al hablar de gnoseogénesis nos referimos a los procesos psicológicos que tienen lugar en la emergencia del conocimiento. Expondremos el problema de una manera general, precisando los pasos importantes necesarios para obtener conocimientos.

\section{Abducción de información}

Entendemos por abducción informacional los procesos psicológicos que tienen lugar al enfocar o centrar la atención en los aspectos del medio que conducen a captar estímulos a través de órganos que fueron calificados por I.P. Pavlov como "analizadores" periféricos o ambientales, más conocidos como "receptores".

Este comportamiento, en términos generales, consiste en orientar los receptores hacia el objeto interesante. La parte pertinente del medio concentra la atención de la persona. Esta reacción fue denominada por Pavlov 
"Chto eto takoie reflek" - el reflejo de ¿qué es esto?. Sokolov (1963) llamó reflejo de orientación a "una reacción generalizada de activación, de preparación para la acción frente a una situación que activa la atención". Dentro de esta reacción se incluía un aspecto gnóstico. Konorski (1967) separó la reacción de orientación de la componente gnóstica, que denominó "reacción de enfoque» ("targeting reaction "). Esta reacción puede ser generada por un estímulo nuevo o por la búsqueda de estímulos (EspinozaVaras 1971).

La reacción de enfoque permitiría obtener de una manera adecuada la información sensorial. Dentro de la actividad cognitiva, el reflejo de enfoque es una modalidad selectiva frente a estímulos exteroceptivos (Treisman, 1969). Su función es seleccionar la información que ha de penetrar el organismo en un momento dado, facilitar su entrada en el analizador correspondiente, y probablemente, inhibir de la información proveniente de analizadores no comprometidos. El reflejo de enfoque es una actividad atencional que participa en una gran variedad de procesos cognitivos. Konorski (1967) señala que la percepción resulta de un determinado reflejo de enfoque "puesto que no todos los estímulos que caen en la superficie receptiva son percibidos».

Mis colaboradores y yo hemos estudiado la reacción de enfoque a un chasquido de corta duración (orden de los milisegundos), administrado por parlantes ubicados en el espacio alrededor de un gato : el animalito se activa buscando con movimientos de orejas, de ojos, de cabeza y cuerpo (según la ubicación) a la fuente sonora. Si el estímulo se repite, el animal deja de prestar atención, y no responde. Si por el contrario, el chasquido se asocia a un refuerzo positivo - un pedacito de carne u otro estímulo apetitoso - el estímulo auditivo adquiere el carácter de un estímulo condicionado excitatorio, y la respuesta de enfoque se convierte en una respuesta preparatoria instrumental alimenticia (Alvarado y Santibáñez-H. 1971, Santibánez-H. y Siegmund 1976,1977).

Si por el contrario, el estímulo auditivo no se refuerza, la reacción aumenta su latencia y luego decae, produciéndose extinción del reflejo, lo que se conoce bajo el nombre de "habituación", que se acompaña por "pérdida del interés" en el estímulo y por supuesto, desatención

El reflejo de enfoque audiovisual es un buen modelo para conocer las bases neuropsicológicas de los procesos perceptuales. Estudiando el problema en el gato y también en el hombre (Siegmund, Stoppa, Santibáñez-H 1987)se observó la secuencia de los diversos componentes (auriculares, oculo-cefálicos y corporales) de esta reacción, que orienta la mácula hacia la fuente sonora. El fenómeno fue estudiado para conocer las estructuras encefálicas envueltas en la reacción.

\section{Codificación de la información sensorial}

La percepción es el primer fenómeno envuelto en la gnoseogénesis. Esta es la tarea que cumplen los sistemas sensoriales, canales nerviosos que transportan la información recogida por los receptores. Esta es transformada en señales de actividad neural que llevan información codificada a estaciones neuronales ubicadas en diferentes niveles del Sistema Neuroendocrino. Una vez codificadas, ellas alcanzan diferentes sectores del cerebro, se transforman en percepciones, $y$ pasan a integrar el mundo o medio subjetivo, virtual, de un individuo concreto.

Las percepciones se integran en "sistemas perceptuales», los cuales son capaces de producir o reproducir los objetos que emergen de una manera tal que permiten a los individuos reconocerlos y diferenciarlos de otros objetos del medio. 
Los receptores o analizadores periféricos no envían en un solo mensaje la totalidad de la información sobre un objeto. De una manera reiterativa diferentes células del receptor se encargan de enviar la información, que es prácticamente una disección sensorial del objeto ; v.gr., una mesa es perceptualmente disociada en bordes verticales, bordes horizontales, ángulos de diferentes orientaciones, etc.. Estas diferentes corrientes informacionales se van integrando por el camino hasta constituir un todo en las unidades sensoriales, digamos, "superiores".

Esta síntesis perceptual de la información tiene un límite, que depende de la capacidad analítica de los receptores frente a los datos recogidos. Los receptores auditivos de las diversas especies tienen diferentes posibilidades de captar información sonora : Los murciélagos captan ultrasonidos, el Homo sapiens, alcanza a escuchar alrededor $15000 \mathrm{~Hz}$. Una persona no capta con sus órganos auditivos los ultrasonidos. Pero el género Homo conoce la existencia de los ultrasonidos, sabe como producirlos y ha desarrollado una tecnología para localizarlos, para usarlos convenientemente, etc.

¿Cómo es posible esto? Gracias a las "prótesis sensoriales», contrapartida de las prótesis efectoras. Las prótesis sensoriales permiten conocer aspectos de la naturaleza que no nos son accesibles directamente, pero que tienen un equivalente virtual en nuestra subjetividad.

La percepción es un integrante importante del conocimiento, pero ella no es todo el conocimiento. Podemos conocer un fenómeno sin percibirlo de una manera directa, como también podemos percibir un fenómeno sin llegar realmente a conocerlo. El conocimiento puede elaborarse partiendo de una percepción directa o de una percepción efectuada a través de una prótesis perceptual.
Las percepciones son fenómenos fenotípicos, puesto que ellas se producen a través de la experiencia. La actividad perceptual se adquiere y las neuronas responsables de una percepción específica adquieren la calidad o propiedad de percibir. Aunque las neuronas estén disponibles, la clave del conocimiento, el contenido, proviene del medio, de cualquiera de los medios descritos anteriormente. La forma de la percepción es neural, y su contenido proviene del medio, es ambiental, mediática.

Konorski en 1948 se propuso integrar las concepciones de Pavlov con las de Sherrington(1906). En este esquema conceptual era necesario integrar conceptos subjetivos como la percepción con la actividad de las neuronas. Esta idea estuvo favorecida por los trabajos de Hubel y Wiesel (1962, 1963, 1977), quienes mostraron que el geniculado lateral contenía neuronas que responden "a bordes», "a esquinas», "a lengüetas», "a bastones" y estudiaron el desarrollo funcional de la corteza visual de gatos y macacos, los campos receptivos, y la interacción binocular. Sin embargo, desde un punto de vista subjetivo, los seres humanos responden con percepciones globales, y sólo el análisis de estas percepciones permite distinguir estos elementos integrados en el percepto subjetivo total. Tengamos presente que la Psicología de las Formas (Koffka 1935) demostró que la percepción no es la suma de unidades perceptuales (sensaciones), como suponía la Psicología asociacionista del Siglo XIX, sino una conformación perceptual de figura y fondo.

Somos incapaces de resolver una palabra en sus componentes acústicos. Una persona analfabeta no puede resolver el sonido de una palabra en sus fonemas, y nadie resuelve las vocablos emitidos en sus componentes kinestésicos. Hasta hace poco nuestra información sobre percepción era puramente subjetiva; en la actualidad podemos completar- 
la con datos neuronales, los cuales nos ponen en conocimiento de su génesis.

Konorski (1967) propuso clasificar las neuronas que participan en un sistema sensorial en "neuronas o unidades de tránsito" las cuales envían la información sensorial codificada a niveles neuronales superiores del sistema sensorial, a las que calificó de "unidades gnósticas" (o de salida).

Hay pruebas neurológicas que apoyan este punto de vista:

a) Lesiones: de las áreas de proyección sensorial (tránsito) producen déficit sensorial, mientras que las lesiones de las áreas de salida o gnósticas no altera la percepción sensorial, pero el afectado no sabe de qué se trata, no entiende el contenido, la categoría perceptual (este es un mecanismo de la afasia).

b) Estimulaciones (Penfield y Rasmusen 1950) : del área de tránsito evocan percepciones relacionadas con el área correspondiente. En el área visual se evocan colores, estrellas, en el área somática; alteraciones del tacto, hormigueos. Por otra parte, estimulaciones de las áreas gnósticas, si estas no están alteradas, hay silencio, no hay respuesta; en cambio, si forman parte de un foco epiléptico, evocan recuerdos, alucinaciones de experiencias vividas. El aura epiléptica de los pacientes corresponde por sus contenidos al tipo de corteza comprometida.

Tengamos presente que las áreas primarias o de tránsito parecen estar determinadas genéticamente, con la salvedad que si estas áreas no entran en función, no son activadas dentro de cierto plazo después del nacimiento, ellas dejan de funcionar normalmente (Zernicki 1991, 1993). Las áreas gnósticas adquieren sus funciones mediante procesos de aprendizaje. Konorski (1967) proponía que las neuronas receptoras de salida tienen una cantidad de conexiones potenciales que se actualizan por un incremento de los contactos sinápticos, o que son creadas por estos.

Estamos en pleno análisis de la concepción neuronal de los procesos psicológicos gnoseogénicos. De esta manera se hace realidad la integración de la información proveniente de diversas disciplinas a fin de generar adecuadamente el correspondiente conocimiento. La posibilidad de integrar a las funciones del Sistema Neuroendocrino los datos de la Psicología subjetivista existía desde muy antiguo. Esta integración fue dificultada por la teoría "protoplasmática del sistema nervioso". Allí se proponía que todo el SN estaba compuesto por una red de canalículos que conectaban todos los puntos de esta estructura. Esta idea fue rechazada con el descubrimiento hecho por Ramón y Cajal de las conexiones sinápticas, y con ello se puso fin a la concepción de la "continuidad neuronal proptoplasmática".

\section{Psicología de la Percepción}

Las primeras formulaciones de la concepción neuronal sináptica tuvo muchos detractores (Barlow 1995). Pero abrió las compuertas a la integración de la actividad neuronal con las percepciones.

Esta idea fue formulada por Konorski (1948) quien sugirió las existencias que "unidades neuronales gnósticas» responsables de las "percepciones unitarias" y en general de las percepciones (Konorski, 1967).

\section{Las unidades neuronales perceptuales gnósticas}

La idea de Konorski consistió en interpretar la estructura, -el sistema perceptual- de cualquier modalidad neuronal como formada por los dos tipos de grupos celulares antes mencionadas, además del receptor : las "unidades de tránsito", que se mantendrían 
dentro del sistema específico de la modalidad sensorial, y las "unidades de salida» que integrarían el último nivel de la actividad neuronal sensorial específica para entregar la información a grupos celulares que pertenecen a una modalidad sensorial diferente, a un área efectora (v.gr. motora) o a unidades responsables de los procesos subjetivos, o a varios de ellos.

Esto implica una estructura por pisos de los sistemas perceptuales, y al mismo tiempo fenómenos de convergencia o divergencia de la información. Las unidades gnósticas podrían ser producto de la convergencia. Este juicio ha sido ampliamente confirmado por la experimentación más reciente.

El estudio de los fenómenos perceptuales muestra que ellos son la actividad funcional de ciertas neuronas o de grupos de ellas. Estas percepciones constituyen la materia prima del conocimiento y también el elemento más importante que gatilla tanto la actividad efectora (movimientos, secresiones, etc), como la actividad subjetiva. Además generan formas complejas de la actividad individual producto de la interacción de los individuos con su medio, y tal vez gracias a esta interacción eventualmente se producirían reorganizaciones funcionales de los genes que mantendrían el proceso de evolución en marcha (Tierney, 1986, Jablonka et al., 1998).

Revisemos algunos datos experimentales para ilustrar con hechos las afirmaciones anteriores.

Barlow et al., (1971) mostraron que las descargas de las células ganglionares retínicas, se alteran cuando los fotoreceptores han absorbido unos pocos cuantos de luz. También mostraron que unos cuantos de luz son suficientes para inhibir las descargas espontáneas de las células ganglionares. La intensidad de la luz que produce inhibición es comparable al umbral absoluto para la activación comportamental.
De Valois et al., (1967) y Talbot et al.,(1968), estudiando los receptores cutáneos, mostraron el principio de "envolturas inferiores", esto es, que la actividad específica de neuronas aisladas puede empezar ya en los receptores auditivos y táctiles. Observaron además que los umbrales para activar los receptores cutáneos (Talbot, 1968) y también para los receptores auditivos son comparables a los umbrales de las reacciones comportamentales (Kiang et al; 1965, Evans, 1978). Newsome, Britten y Moushon (1989) y Britten et al., (1992), registrando neuronas sensoriales aisladas únicas del área temporal media (MT, v 5) de monos activos, observaron que la mayoría de las células responden selectivamente a tipos de movimientos específicos de puntos distribuidos al azar. La sensibilidad de estas neuronas fue examinada en una pantalla de computador variando la proporción de puntos que se mueven coherentemente en una dirección determinada ("puntos coherentes»), comparándolos con los desplazamientos al azar de otros puntos, "puntos incoherentes».

Los animales pueden ser entrenados en una prueba de reflejos condicionados, a asociar los puntos coherentes con la ejecución de un movimiento determinado. Si se encontraba una célula del área temporal media (MT) que respondía al desplazamiento de los puntos coherentes, se medía el umbral óptimo para actuar sobre la célula (posición, número de puntos). La célula era registrada cuando los animalitos ejecutaban los movimientos asociados al desplazamiento de los puntos. Los experimentadores buscaron la frecuencia con que debían dar una respuesta correcta si disponían de la información adecuada suministrada por un sola célula, y controlaban lo que sucedía cuando los puntos coherentes invertían su trayectoria. Los resultados señalaron que el promedio de la performance calculada desde una neurona aislada correspondía muy bien con el comportamiento real del mono. 
Estas neuronas están al término de la vía final común (unidades de salida, según Konorski) donde converge la información de diferentes unidades portadoras de varios aspectos informacionales pertinentes, al mismo tiempo que excluyen otras informaciones irrelevantes.

Esta es una demostración muy impresionante del hecho que una sola neurona puede tener la sensibilidad y los detectores confiables de complejos patrones espaciotemporales de excitación.

No obstante, es posible que la información que alcance el último eslabón de la vía final común sea combinado de una manera diferente a la que hemos considerado. Por ejemplo, Movshon et al., (1985) encontraron neuronas pertenecientes a la misma área MT que se activaban en la intersección formada por un par de rasguños de la piel que se cruzan, más bien que por cada componente del estímulo, es decir, por cada región aislada. Este hecho indica que la actividad de esas células no se debe sólo a la información de las áreas v1 y v2, sino también a que pueden participar otros niveles de integración.

La representación de manos y caras en la corteza infero-temporal ha sido estudiada por Gross et al., (1992). Estos autores mostraron que hay células que responden a manos y caras de una manera categorial, como había indicado Konorski (1967) al caracterizar las "percepciones unitarias".

La percepción de impulsos únicos ha sido estudiada por Vallbo(1995), usando el método de microestimulación. Estimularon el dedo índice, y con un electrodo intraneural, registraron un axón único de las células receptoras. Una vez registrado, cambiaron el electrodo de registro por uno de estimulación. De este modo inyectaron en el axón seleccionado una serie de impulsos neurales que entraron en el Sistema Nervioso. El sujeto localizó la estimulación en el lu- gar original. Si se aumentaba la intensidad de estímulo, aparecía una segunda localización, y un nuevo incremento, reclutaba una tercera localización.

\section{Grupos neuronales perceptuales-gnósticos}

Considerando la convergencia de las vías aferentes a las neuronas de niveles superiores, es fácil de entender que existan células de estos niveles capaces de integrar una gran cantidad de información proveniente de los medios en los cuales operan las habilidades perceptuales de los individuos. Se han descrito diversos tipos de neuronas que responden específicamente a ciertas formas objetivas. Estas no son células únicas, sino grupos neuronales. Unas de las más curiosas son las mal llamadas "células abuelas" ("grandmother cells"), las cuales son capaces de reaccionar cuando la madre del sujeto aparece en el campo visual; pero no solo la madre tiene sus células específicas, sino que hay otras configuraciones estimulantes que también están representadas en grupos de células en el área sensorial correspondiente. Se han descrito alrededor de 18.000 neuronas de este tipo (Barlow, 1995). Harris (1980) es de la opinión que aunque fuese razonable postular la existencia de una unidad neuronal para cada posible tipo de percepción, es difícil pensar que exista un número suficiente de neuronas capaces de realizar esta tarea. Por lo tanto, propone que estas percepciones complejas son producto de actividad de conjuntos. Barlow (1995) sostiene que el fenómeno de la especialización perceptual es un efecto adaptativo resultante de la interacción neuronal que genera cambios asociativos entre las células que podrían ser facilitadas por las exigencias de los medios interactuantes.

El procesamiento visual en primates envuelve muchos centros subcorticales, así como también numerosas áreas corticales. 
Hay evidencias anatómicas y fisiológicas que indican que las estructuras están organizadas en jerarquías que incluyen hasta 10 niveles de procesamiento. A cada nivel concurren corrientes de procesamiento paralelos que incluyen diferentes tipos de neuronas. Pueden encontrarse líneas directas de progreso de las corrientes de información, independientes unas de otras, líneas de corrientes en interacción en diferentes pisos, y líneas en que hay convergencia y divergencia en los diferentes niveles. Se han descrito alrededor de 32 áreas visuales identificadas con varios criterios. Téngase presente que en el interior de la corteza visual, la información es mediada por un impresionante conjunto de conexiones cortico-corticales reveladas por técnicas de trazadores.

Nuestras corrientes perceptuales derivadas de varios de los niveles pueden indicar orientación (forma), velocidad (movimiento), composición espectral (color), disparidad binocular (profundidad).

Los trabajos de Mc Naughton, Knierim y Wilson (1995) han puesto en evidencia el rol predominante que juega el sistema vestibular en la construcción de las representaciones cognitivas del medio, y en la computación óptima de las trayectorias hacia los objetos que se localizan visualmente. Es el así llamado sistema direccional o sentido de la dirección, el cual aparece también envuelto en la integración de señales de la velocidad angular. Este sistema puede adecuarse a organizar su acción después de cada $360^{\circ}$. Es decir, es operativo cada $360^{\circ}$. Este sistema funciona de una manera compleja. Queremos sólo mencionar que una ratita puesta en un sistema rotatorio, a la cual se fija un lugar que la atrae, es capaz de llegar al objetivo, aunque se apague la luz, o se haga desaparecer el objeto.

Las lesiones del Hipocampo suprimen radicalmente este comportamiento, es decir, se suprime de esta manera la representación cognitiva del espacio. Grupos de células hipocampales son activadas selectivamente por elementos específicos de un espacio ambiental. Estas transmiten en conjunto, códigos espaciales que son suficientemente precisos para hacer predictibles la posición del animalito en la distancia de unos pocos centímetros por el registro simultáneo de 70 a 150 células del Hipocampo. Estas son células piramidales han sido bautizadas como “células de lugar». El sistema de referencia direccional no es aún bien conocido.

Andersen (1989) y Andersen et al., (1985, 1990), en una serie de trabajos, nos ha hecho saber que la corteza parietal no es estrictamente visual ni tampoco estrictamente motora. Ella integra fenómenos visuales con fenómenos motores, integraciones visuomotoras, incluyendo transformaciones para la determinación de sitios especiales y la coordinación de planos de movimiento. Esta función es fundamental para el desarrollo del comportamiento guiado visualmente. Ella es controlada por claves retínicas que deben ser transformadas en la activación de músculos que permiten el movimiento. Esta función se cumple en la corteza temporal posterior, usando un código poblacional, formado por una operación específica que integra o comparte sistemáticamente parámetro retínicos y extra retinianos (ojo, cabeza). Se ha encontrado actividad relacionada con la planificación de los movimientos oculares en el área intraparietal que controla los movimientos sacádicos. La actividad relacionada con la planificación parece codificar los movimientos que el animal intenta hacer.

\section{Procesamiento Neuropsicológico de Actividades Psíquicas Complejas}

La experimentación neuropsicológica ha hecho contribuciones importantes al conocimiento de la génesis de la imágenes perceptuales, de las imágenes subjetivas, de 
la relación del pensamiento con la producción de imágenes, de las representaciones espaciales abstractas, del pensamiento deductivo, entre otros. Presentaremos un suscinto panorama de la situación actual de algunas de estas cuestiones.

El problema de la interacción entre imágenes perceptuales e imágenes subjetivas es conocido de larga data. Konorski (1967) llamó la atención sobre la relación existente entre el aspecto gnóstico de las imágenes y las percepciones, haciendo notar que las primeras representan una forma más pura de activación gnóstica, referida al objeto, porque ellas no están directamente bajo la influencia de la información proveniente de las vías sensoriales específicas (op.cit. p. 181).

Por otra parte, la evocación de una imagen subjetiva puede ser considerada un fenómeno análogo a un reflejo condicionado en el cual la imagen subjetiva es equivalente a una respuesta condicionada generada mediante la satisfacción de una necesidad por el objeto que ha producido una imagen perceptual. De esta manera la emergencia de la necesidad sin la presencia del objeto que la satisface evoca la imagen de éste. Otra categoría de asociaciones que llevan a la producción de imágenes es la asociación "percepto-perceptual". Esta asociación es la consecuencia de la conexión o asociación generada por los fenómenos gnósticos que emergen en continuidad espacial o temporal. Así, la percepción de uno genera la imagen del otro. Si se hace coincidir de una manera sistemática una luz con un tono, la luz adquiere la habilidad de evocar la imagen auditiva del otro (op.cit. 183-186). Esta situación es típica al asociarse la voz de una persona con la presencia de la misma. $\mathrm{Al}$ escuchar la voz aparece la imagen y tal vez otras imágenes asociadas con la persona. Ahora bien, en el caso del locutor radial nunca visto, su voz no está asociada con la figura del locutor sino con las señales que caracterizan la emisora, o con el nombre del locutor.
Para Konorski (op.cit. 184-185) hay otros dos factores que son determinantes en la asociación que conduce a la formación de las imágenes subjetivas: un cierto incremento de un estado general de activación, lo cual aumenta la excitabilidad de las neuronas envueltas en la generación de las imágenes subjetivas y naturalmente la participación de neuronas específicas extraretínicas las cuales hemos mencionado al comienzo de este capítulo.

En tiempos recientes se ha dedicado mucho esfuerzo al estudio de la interacción entre las imágenes subjetivas y las percepciones, las cuales demuestran que estos dos fenómenos comparten integraciones neurales comunes. Técnicas tomográficas de emisión de positrones (PET) han suministrado evidencias mostrando que las imágenes subjetivas activan partes de las corteza visual topográficamente organizada.

Si alguien percibe unas pocas características de un objeto, las cuales no permiten tener una percepción completa del objeto, la información proveniente de este permite varias posibilidades perceptuales particulares o concretas. Esta percepción ineficiente tendría la propiedad de activar selectivamente un "modelo" de imagen almacenado en el sistema mnémico visual cuya forma constituye el mejor equivalente de la percepción imperfecta (Lowe, 1985, Kosslyn, 1980, Kosslyn et al. 1990). Este sería un proceso que permite establecer el reconocimiento de objetos. Cave y Kosslyn (1989) sostienen que la imagen generada desde el conjunto de "modelos" almacenados puede contribuir a aumentar el número de caracteres durante el acto de reconocimiento. Estos y otros autores concluyen que la imagen de un objeto previo es incorporada a la imagen perceptual si el sujeto ha sido sometido a la acción del mismo objeto dos veces consecutivas. En tanto que si el objeto es seguido por un objeto de otra conformación, el reconoci- 
miento es más lento que cuando el objetoevocado fue el mismo que el objeto primario. El tiempo de evaluación incrementa linealmente con la disparidad de los tamaños de los dos objetos (Bundesen y Larsen, 1981).

La integración neural de los procesos descritos tiene una larga historia. El hecho que existan abundantes conexiones recíprocas entre áreas retínicas y extraretínicas - en consecuencia conexiones de retroalimentación desde los centros visuales superiores - prestan credibilidad a las interpretaciones expuestas. Sin embargo, estas conexiones recíprocas no son exactamente el revés unas de las otras. Las vías eferentes contienen conexiones más difusas que las vías aferentes. Zeki y Shipp (1988) han mostrado que el área mediotemporal (MT,-v1) recibe información desde las “bandas gruesas" del área v2 y envía información de retroalimentación tanto a las "bandas gruesas" como a las "bandas delgadas» y también a las "interbandas" del área v2. Hay varias interpretaciones de estos hechos que constituyen hipótesis susceptibles de aportar elementos al conocimiento de los fenómenos del reconocimiento de objetos. Hay que agregar que las estructuras corticales envían axones a las capas profundas del tálamo, ésta a su vez envía información a la corteza, la cual termina en la capa 4. La retroalimentación talámica difiere de la retroalimentación corticocortical las cuales generalmente terminan en las capas superficiales (1 ó 2) o en capas profundas (5 ó 6), más bien que en la capa 4 (Munford, 1991).

Muchas de las propiedades de las imágenes subjetivas remedan las imágenes perceptuales, lo que no es de extrañar pues ambas tienen integraciones comunes como ya fue sugerido por Konorski (1967, p. 185187). Pero no sólo las imágenes y las percepciones pueden tener aspectos comunes en su génesis sino también imágenes, ilusiones y aún las alucinaciones. (Konorski op. cit. pp. 174-180). Las percepciones y las imágenes parecen estar envueltas en la génesis de los movimientos en un complejo fenómeno de integración de imágenes visuales y de imágenes propioceptivas.

La distinción entre imágenes perceptuales e imágenes subjetivas provenientes del cerebro mismo es un problema que tiene varios aspectos. Uno de ellos es conocer si las imágenes subjetivas integran las mismas representaciones que originalmente se producen durante las percepciones, o si ellas son consecuencia de la influencia del lenguaje sobre la actividad subjetiva. Las imágenes subjetivas se generan en el área extraestriada. Autores como Paivio (1971), Shepard (1978) y Kosslyn (1980) han desarrollado un importante trabajo experimental para establecer distinciones entre imágenes y pensamiento verbal, para presentar las imágenes y el pensamiento verbal, y las imágenes en función del procesamiento informacional.

De Renzin y Spinnler (1967), utilizando el Test de Ishihara, observaron que pacientes con lesiones corticales unilaterales presentaban, tanto deterioro de la visión de colores, como de la habilidad para describir los colores de imágenes coloreadas retenidas en la memoria. Beauvois y Saillant (1985), en pacientes con desconexión visuo-verbal advirtieron que podían realizar con éxito tareas relacionadas puramente con colores, pero no realizar tareas que estaban asociadas a una etiqueta verbal (nombrar colores). Levine, Warach y Farah (1985) realizaron experimentos que ponen en evidencia que tanto las imágenes subjetivas como las perceptuales comparten representaciones específicas para algunas modalidades sensoriales.

Goldenberg y sus colegas (1987, 1989, $1991,1992)$ han realizado una serie de estudios de flujo sanguíneo durante la producción de imágenes subjetivas usando SPECT (tomografía computarizada por emisión de 
fotones únicos). El registro se llevaba a cabo cuando se evocaban imágenes. El control consistía en evocar situaciones sin la presencia de imágenes. En todos estos experimentos las imágenes visuales se encuentran asociadas con activación de la corteza temporal y occipital.

Charlot et al., (1992) usando la técnica SPECT encontraron también que el flujo sanguíneo aumentaba en el área visual asociativa, incluyendo la corteza visual, si los sujetos generaban y examinaban imágenes subjetivas. Por su parte, Le Bihan et al., (1992) empleando la resonancia magnética durante la producción de imágenes subjetivas, encontraron que el área 17 estaba envuelta en la producción tanto de imágenes subjetivas como perceptuales.

La complejidad relacional ("relational complexity») es un concepto introducido por Robin y Holyoak (1995) con la intención de facilitar el conocimiento de las funciones de la corteza prefrontal. Las funciones de la corteza prefrontal tocan una cantidad de funciones relacionadas entre sí, y éstas con las funciones mnémicas. Fuster (1989) puso de relieve el significado funcional del lóbulo frontal. Esta estructura ejercería el control operativo, el control atencional basado en la representación interna del contexto, la creación y el uso de episodios gnósticos y las secuencias de las acciones.

La idea de Robin y Holyoak (1995) es considerar las funciones de la corteza prefrontal como responsable de la adquisición y el uso de nexos gnósticos explícitos al servicio de una meta u objetivo. Este conocimiento explícito se adquiere automáticamente de una manera rápida y sin esfuerzo. Este es capaz de diferenciar "roles" de "complementos". En niveles tempranos tanto filo como ontogenéticos, un animal reacciona a objetivos sin someterlos a ningún análisis dimensional explícito. Estudios de la actividad clasificatoria de los niños ponen en evidencia que estos pueden enfrentar globalmente una manzana con otra. Sólo más tarde serán capaces de parear objetos por características complementarias como el color. La manzana "in toto" es el "rol", el color rojo, el "complemento". De esta manera pueden usar el complemento como elemento clasificatorio, y parear, por ejemplo, la "manzana roja" con un "bloque rojo". La habilidad básica es holística, totalizante, el uso del complemento es "abstractivo". El procesamiento dimensional explícito en el cual toman parte la región prefrontal, parece envolver la interacción "rol-complemento", "totalidadelemento integrante". (Halford 1993)-

Los procesos relacionantes cambian con lesiones de la corteza prefrontal, las cuales alteran las habilidades para establecer mapas relacionados con mapas de niveles de sistemas, en vertebrados, primates y humanos. La corteza prefrontal tiene conexiones recíprocas extendidas a un amplio abanico de estructuras corticales y subcorticales, incluyendo casi la totalidad de las áreas del sistema nervioso central, lo cual es una indicación del rol integrativo de esta región que evidentemente está envuelta en el control, tanto del comportamiento como de los procesos subjetivos. Las lesiones de las diferentes áreas prefrontales conforman síndromes específicos. Las lesiones del área dorsolateral, incluyendo la región periprincipales, alteran la habilidad para planificar, la concentración, la memoria de corta duración y el aprendizaje de reflejos condicionados con inhibición de retardo ( Knight 1991).

En síntesis, considerando los resultados de los registros neuronales unitarios y los datos electrofisiológicos, la corteza prefrontal es el centro integrador de una serie de funciones fundamentales (Fuster 1973, 1989) : mantiene la memoria operacional por intermedio de la región dorso central, evita interferencias por estímulos interpuestos entre una señal y el alcance del objetivo 
(Lawicka 1979., Drewe, 1975), por intermedio de la región periarcuata, mantiene la efectividad del retardo y determina la inhibición del efecto de las interferencias por intermedio de la región orbito-frontal (Jacobson 1935). Al perecer, estas tres regiones actúan integradamente generando un comportamiento que conduce a un objeto específico en un tiempo determinado..

El pensamiento deductivo estás siendo sometido a una intensa investigación. Hay diversas regiones del cerebro que aparecen comprometidas en esta actividad.

Hay autores que sostienen que el razonamiento deductivo está basado en principios formales de inferencia como aquellos de la Lógica. Sostienen que estos principios son puestos automáticamente en juego al derivar conclusiones a partir de premisas. Estas representaciones "proposicionales" son consecuencia de símbolos sintácticamente estructurados en su lenguaje mental, análogo a una prueba lógica (Braine, Raiser y Rumain, 1984). Una postulación alternativa confiere prominencia al rol de los modelos subjetivos, lo cual no significa un rechazo a la idea de las representaciones proposicionales, sino que estas son consideradas como informaciones que entran en un proceso que constituye un modelo subjetivo que corresponde a la situación descrita en el discurso verbal.

Experimentos de Byrne y Johnson-Laird (1989) han comparado la habilidad predictiva de ambos enfoques. 18 personas usaron ambos modelos para hacer inferencias. Los resultados indican que las inferencias hechas con el modelo subjetivo inferencial tienen una capacidad de predicción aplastantemente mayor que las del modelo basado en reglas formales.

Johnson-Laird $(1983 ; 1993)$ sostiene que tanto la deducción como la inducción y otros procesos creativos se llevan a cabo sobre la base de modelos subjetivos (mentales) más que sobre modelos de representación proposicional basados en reglas formales. El principio que subyace es que la comprensión del discurso lleva un modelo de la situación en cuestión que es coincidente con una creada por la percepción o por la representación (imagen) de los sucesos y no por aquello que simplemente han sido dicho sobre ellos (Johnson-Laird 1970).

El modelo subjetivo se ajusta a la neuropsicología del pensamiento. En contradicción con la idea de que el razonamiento es verbal (Polk y Newell, 1922), o a que está conformado por reglas formales, (Rips 1983), este modelo sugiere que el razonamiento tiene un componente mayoritario que no es verbal, esto es, que la construcción de modelos inferenciales corresponde a la estructura de situaciones. Este punto de vista predice que el hemisferio derecho debe jugar un rol importante en los procesos inferenciales. Caramaza et al., (1976) observaron que pacientes con lesiones en el hemisferio derecho presentaban serias alteraciones de sus capacidades inferenciales. McDonalds y Wales (1986) señalaron que el hemisferio derecho parece integrar el conocimiento visuo-espacial, lo cual permite suponer que en alguna medida imágenes subjetivas visuales intervienen en los procesos inferenciales. El hemisferio derecho estaría envuelto en la génesis de los procesos inferenciales.

El cerebro tiene la propiedad de operar con representaciones abstractas del espacio. Esta capacidad deriva de la integración de la información proveniente de la inclinación de las señales visuales con la información acerca de la posición de los glóbulos oculares, elángulo de inclinación y la posición de la cabeza. Estas señales son integradas en la corteza parietal inferior (Andersen et al., 1985) para formar una distribución espacial específica y ordenada que ha sido tipificada como campo de representación lineal (Zipser y Andersen 1988). El área lateral parietal interna integra posiciones de la 
cabeza y del cuerpo y movimientos de los globos oculares (movimiento sacádico) con señales retínicas para codificar el espacio en coordenadas cefalo-corporales (Balint 1909, Wagman 1967, Mountcastle et al., 1975, Lynch I y Mc Laren 1989). Muchas células procesan inclinación y disparidad de señales, haciendo posible la representación de situaciones con respecto al cuerpo. Neuronas de esta área integran información de la posición de los ojos, de la cabeza y el ángulo de inclinación, como también la información acerca de la posición de la retina. Al parecer, representa objetivos centrados en coordinadas específicas.

\section{Factores Motivacionales Específicos que Intervienen en la Gnoseogénesis}

Llamamos factores motivacionales aquellos factores que mantienen activo el interés de la persona envuelta en un proceso de génesis de conocimiento. Estos factores facilitan la atención centrada en la observación del fenómeno en estudio por largos períodos, permiten advertir variaciones en el comportamiento del objeto de observación, y al mismo tiempo, estimulan la aparición de diversas formas de acciones del observador sobre la situación en estudio. No hay conocimiento sin una motivación, proceso psicofisiológico que mantiene viva, activa, la necesidad de penetrar en los rincones gnósticos del objeto de estudio.

La motivación puede ser de muy diversa naturaleza; puede variar desde la auténtica curiosidad hasta la necesidad de obtener dinero o prestigio (Pakard 1959). A veces hay más de un tipo de motivación envuelto en estos procesos. La curiosidad es una motivación muy difundida en la adquisición de conocimiento, no solo en el Homo sapiens, sino en diferentes especies de animales.

Konorski (1968) señala que la función de las neuronas envueltas en la percepción son facilitadas por el aumento de la reactividad que se produce gracias a los procesos motivacionales. Con diferentes colaboradores hemos efectuado trabajos para determinar el efecto de la motivación sobre la actividad cerebral. Hemos medido el grado de excitabilidad de la formación reticular, en la corteza cerebral y de núcleos subcorticales de las vías sensoriales. Hemos observado, por ejemplo, que, en gatos, la excitabilidad de estas estructuras aumenta con la deprivación alimenticia aguda de hasta un máximo de 60 horas. Más allá de este límite, la excitabilidad decae. Hemos comparado el efecto de diversas maniobras motivacionales con el efecto de una estimulación eléctrica de bajo voltaje y frecuencia moderada, consiguiendo el mismo efecto que produce la deprivación. Una situación análoga se produce con la motivación de miedo: aumento de la excitabilidad general del Sistema Neuroendocrino (Santibáñez-H. et al., 1966).

Los individuos altamente motivados en la producción de conocimientos tienen una dedicación al trabajo que muchas veces recuerda la adicción a ciertas drogas. Las personas que están dedicadas a la creación artística o científica viven pendientes de su trabajo. Pueden trabajar desenfrenadamente por un número considerable de horas, aparentemente sin fatigarse y sin caer en una situación de distréss.

\section{Manipulación Gnoseogénica}

No hay génesis de conocimiento sin un estado motivacional que module este proceso, y no hay conocimiento sin manipulación, sin observar el efecto de acciones que aparecen sobre el objeto.

La generación de conocimiento es un proceso de aprendizaje. Este aprendizaje tiene varias fases : va desde la localización del fenómeno-objeto hasta la constatación de los 
cambios que este experimenta al ser sometido a diversas condiciones manipulativas sean estas naturales o experimentales. Esta categoría de actividad plástica configura una compleja modulación de las funciones subjetivas y comportamentales de los sujetos cognoscentes que están en una estrecha interacción temporo-espacial entre sí y con el objeto (Anojin, 1978).

La génesis del conocimiento obviamente no es entonces, una cuestión de carácter puramente subjetivo; incluye también actividades comportamentales que son de importancia decisiva, donde debemos incluir toda la actividad experimental y sus aplicaciones tecnológicas.

La subjetividad es responsable de la virtualidad de los procesos gnósticos, los cuales pueden evadir las condiciones espacio-temporales. El comportamiento es responsable de la operatividad e instrumentalidad de ellos. Ambos aspectos en interacción son responsables de la predicción y anticipación de la dinámica de los objetos de conocimiento. Todo conocimiento implica la anticipación y predicción del efecto de una operatoria sobre el objeto.

Tengamos presente que si a un infante de pocos meses se le introduce en su campo visual un objeto, tiende sus manitos para cogerlo. Por otro lado, en nuestra cultura es muy corriente que si a alguien le mostramos un objeto nuevo para él, dice: "A ver, deja verlo", y extiende la mano para asirlo. Obviamente no pide ver el objeto, sino quiere examinarlo con otro órgano de los sentidos además de la visión.

Este compromiso comportamental envuelve una condición necesaria en el desarrollo de una actividad gnóstica: la exploración y la experimentación. Es una actividad que desarrollan en un impresionante nivel los mamíferos y las aves. Los gatos, los perros, son increiblemente curiosos. No solo observan, sino que con sus miembros ante- riores dan golpes, o simplemente manipulan los objetos. Es interesante hacer reaccionar al objeto de conocimiento lo cual obviamente aporta más elementos a su conocimiento.

Ahora, si consideramos la manipulación en la búsqueda de conocimiento fundada sobre bases metodológicas experimentales, la manipulación adquiere una amplitud considerable. Dependiendo del objeto de estudio y las relaciones temporo-espaciales existentes entre el objeto, hecho o suceso, y quienes conocen estos fenómenos, variarán las formas de abordaje que se utilicen. Estos estudios van desde los componentes atómicos hasta el inicio de la galaxia, y probablemente del universo.

La coincidencia temporal o sincronía entre el o los investigadores y el fenómeno-objeto estudiado, puede variar desde la simultaneidad existencial hasta un desfase temporal de millones de años.

Todos los procedimientos experimentales son manipulaciones destinadas a responder las preguntas que un investigador dirige al objeto en proceso de conocimiento.

\section{El Conocimiento y sus Proyecciones Socio-Naturales}

El conocimiento, como todo tipo de fenómeno, puede ser concebido, discutido y analizado desde cualquier ángulo disciplinario. Sin embargo, lo que se necesita es "conocer el conocimiento». La reflexión, por muy sofisticada y brillante que ella sea, no produce el conocimiento, sino crea diferentes interpretaciones de este proceso. A propósito, en la primavera de 1845 Marx (1969) formulaba su famosa 11 Tesis "Los filósofos han interpretado el mundo de diferentes maneras, ha llegado el tiempo de cambiarlo». Recientemente, Bunge (2001) sostiene que la Filosofía está estancada, presa de ocho achaques graves, a saber: excesiva profesionalización, confusión del 
profesionalismo con el oscurantismo, uso de lenguaje obsesivo, idealismo, atención exagerada a miniproblemas y juegos académicos de moda, formalismo insubstancial o insubstancialidad informal, fragmentarismo, aforismo, y el "distanciamiento de los motores intelectuales de la civilización moderna como ciencia, tecnología e ideología a través de una especulación anacrónica y primitiva». Agrega que la "mayor parte de los filósofos contemporáneos no tienen los pies en la tierra, ni los ojos en el cielo». Es de la opinión que la integración gnóstica de datos provenientes de la psicología al ser tratados con las técnicas utilizadas en el estudio del sistema neuroendocrino constituyen un real progreso del conocimiento. Como hemos mencionado, esta idea fue propuesta por Konorski en 1948 a desarrollada en su último libro en 1968. Justamente, publicamos (Santibáñez-H. y Osorio 1998, 1999) un replanteamiento del objeto de la Psicología derivado de la interacción entre el ser viviente y los diferentes medios con los cuales interactúa.

El conocimiento es claramente el producto de la mencionada interacción. Constituye una herramienta fundamental para el proceso de adaptación, tanto individual como específico (Tierney, 1986; Jablonka et al, 1998). Adaptación implica resolver problemas, buscar los conocimientos que permitan solucionar los problemas que dificultan la adaptación, a través de descubrimientos, invenciones o creación de cosas y situaciones, las cuales hacen posible modificar intencionalmente determinados fenómenos concretos que operan en contra de la adaptación.

En términos generales, podemos, tal vez, distinguir entre conocimientos empíricos y conocimientos epistémicos. Sin embrago, todos los procesos gnósticos tienen una dinámica particular independiente de su carácter empírico o epistémico: ellos son producto de la interacción reiterativa, mantenida por un cierto lapso, entre el objeto, fenómeno, o suceso analizado, y el individuo que lo con- templa u observa. Esta interacción tiene una relación espacial específica.

Hemos dicho que la percepción es abstractiva, limitada a la información que suministran los receptores utilizados para captarla, y por las condiciones en las cuales se encuentra el objeto durante el desarrollo perceptual. Es decir, la abstracción perceptual suministra una imagen que está muy lejos de ser una reproducción completa de todos los atributos peculiares del fenómeno considerado. Por esta razón la percepción no es idéntica al conocimiento.

Esto no significa que esta abstracción perceptiva inicial sea completamente inútil para el progreso del conocimiento. Por el contrario, es suficiente para identificar el fenómeno contemplado, y así poder integrar la información suministrada por percepciones sucesivas. Por otra parte, es una señal inequívoca de la realidad factual del medio al cual pertenece el objeto, es decir, que existen independientemente de la conciencia de quien conoce. Es evidente que esta abstracción, al no integrar todos los rasgos que conforman lo esencial del objeto, no alcanza a constituir un concepto, si no que una etapa previa: una noción (Marx,1951,1974; Engels, 1975; Ilyenkov, 1982). El paso de noción a concepto implica no sólo la abducción si no de la totalidad de la información sensorial que pueda generar el objeto, al menos lo suficiente para alcanzar el umbral informacional necesario para aprehender los rasgos sensoriales esenciales de éste, además de las interacciones de éste con otros objetos que constituyen el medio al cual pertenece, como también su génesis, su desarrollo y su evolución.

El proceso de conocimiento es una interacción en espiral que va de lo concreto a lo abstracto; éste se enriquece en las sucesivas percepciones integrando cada vez más información del objeto, con el consiguiente aumento de la habilidad de lo abstracto para reflejar lo concreto. Considerando el problema en esta 
perspectiva lo concreto-abstracto" forma una unidad dialéctica. Lo concreto, según Marx, es la unidad en la multiplicidad, y esta unidad en lo múltiple queda involucrada en la abstracción. (Marx, 1974)

Es también de suyo claro, que la contemplación del objeto en un estado de inmovilidad o quietud no genera la información necesaria para pasar de la noción al concepto. Se necesita tener el objeto en fase dinámica, es decir, en movimiento. El conocimiento empírico implica necesariamente el objeto en movimiento. Esta fase se obtiene a través del uso que se quiere hacer del objeto, vale decir, a través de un aprendizaje por ensayo y error y a un aprendizaje asociativo. En el conocimiento epistémico el objeto se mueve a través de la tecnología de experimentación o de la reglada observación de los objetos que se transforman por cuenta propia. Esto a través de aprendizajes más elaborados y complejos, como las inferencias o hipótesis. De este modo, tanto el conocimiento empírico como el epistémico tienen formas de operar sobre el objeto en movimiento, lo cual implica un comportamiento manipulativo sobre la concreción objetal. Es decir, de una conducta, una manipulación plástica de algún tipo que el observador ejerce sobre el objeto.

Así se establece un hecho: quien conoce, integra comportamientos con procesos subjetivos. La operación comportamental gnóstica debe ajustarse a dos parámetros: la concreción del objeto, y la direccionalidad inquisitiva de la maniobra. La operación subjetiva es abstraer elementos sensoriales, relacionales, genéticos y evolutivos hasta reproducir el objeto en la concreción de su multiplicidad.

El conocimiento es un instrumento psicológico que confiere una gran versatilidad operativa sobre el medio. Permite prever la marcha de un proceso o fenómeno dentro de los límites espacio-temporales que han condicionado la génesis de su conocimiento. Por lo tanto permite predecir o pronosticar el efecto que una determinada influencia intencional tenga sobre el objeto, además de conferir la habilidad de reproducir, recrear o modificar el objeto, fenómeno o situación, una vez conocido.

Es así como el conocimiento es la base de la creación cultural en cualquiera de sus formas. Sin embargo, la utilización social de un conocimiento puede recaer en un elemento para "beneficiar" o bien para "perjudicar o destruir» la naturaleza y sus integrantes. Hemos propuesto (Santibáñez-H., 1997) designar los aportes benéficos con la denominación de "cultura", y los dañinos como "anticultura». El conocimiento crea, entonces una fenomenología unitaria que encierra una diada contradictoria "cultura anticultura" cuyo despliegue socialmente condicionado puede ser favorable o desfavorable al desarrollo armónico de la naturaleza y sus integrantes. Esta alternativa es especialmente observable en la dinámica de la tecnología que, aún alcanzando un alto grado de eficiencia puede generar un alto grado de deshumanización.

\section{Referencias}

Alvarado, M., and G. Santibañez-H. 1971 Targeting reflex: some features and inhibition. Acta Neurobiol. Experimentalis; 31: 31-45.

AnDERSEN, R. A., 1989 Visual and eyemovement functions of the parietal cortex. Annual Rev. Neurosci. 12: 377-455.

Andersen, R. A., R.M. Bracewell, S. Barash, J. W. Guadt, AND L. Fogassi., 1990. Eye position effects on visual, memory, and saccade-related activity in areas L. I. P. 7a and of macaque. J. Neurosci. 10: 1176-1196".

Andersen, R.A., C. Asanuma And, W. M. Covan. 1985 Callosal and prefrontal associational projecting cell populations in area 7a of macagua monkey: a shedy using 
retrogradely transported dyes. J. Comp. Neurol . 232: 443-455.

ANOJIN, P.K. , 1962 Reflexión anticipatoria de la realidad (en ruso). Voprosy filosofi 97111.

ANOJIN, P.K., 1978 Beitrage zu allgemeine Theorie des funktionellen System. Brain and Behaviour Research. Monograph series. VEB Gustav Fischer Verlag. 4p. 320.

BACON F. (1620). 1982. Das Neue Organon (The advance of learning and Novum Organon) Akademie-Verlag. Berlín D.D.R., Pp. 306.

BALint, R., 1909 Seelenlähmung des Shanens Optische Ataxie, Raumliche Störnng der Anfmerksannkeit. Psychiat. Neurol. 25: 51-81.

Barlow, H. B., 1972. Single unit and sensation: a neuron doctrine for perceptual psychology perception. 1:371-394.

BARLOW, H. B., 1985. The role of a single neurons in the psychology of percepcion. Quaterly journal of experimental psychology(A). 37: 121-145.

BARLOW, H. B., 1995. The neuron doctrine of perception En M. S. Gazzaniga, ed. a Bredford book. The MIT Press Cambridge, Massachusetts, London, England. p. 415-435.

BarLOW, H. B., W.R. LeVICK, AND M. YoON. 1971. Responses to single quanta of light in retinal ganglion call of the cat Vision Research 11 (suppl.3): 87-101

Beauvois, M. F. and B. Saillant, 1985 Optic afasia for colours and colour agnosia: A. distinction between visual and visuo-verbal impairment in the processing of colours. Cognitive Neuropsychol. 2:1-48.

BERNARD, C. 1879. Leçons sus les phénomènes de la vie commune aux animaux et aux vegetaux" Baillière et Fils, Paris.

BONNER, J. T. 1989. The evolution of culture in animals. Princenton University Press. Princeton, New Jersey. Pp.204.
BRAINE, M.D.S., B.J.ReISER, AND B. RuMAIN, 1984. Some empirical justification for a theory of natural propositional logic. In the Psychology of Learning and motivation, vol. 18. New York: Academy Press.

Britten, K. H., M.N. Shadlen, W.T. Newsome, and J.A. Movshon, 1992. The analisis of visual motion: A comparision of neuronal and psychophysical performance. J. Neurosci. 12: 4745-4768.

Bundesen, C., AND A. LaRSEN, 1981. Mental transformations of size and orientation En A. Baddeley, and J. Long, eds. Attention and Performance, vol. 9 Hillsdale, N.J.: Erlbaum Pp. 279-294.

Bunge, M. 2001. Philosophy in crisis: not dead, but freading water. Free Inquiry 21:29-31. Buffalo.

BYRNE, R.M. J., AND P.N. JOHNSON-LAIRD, 1989. Spatial reasoning. J. Mem. Lang 28:564-575.

Caramazza, A., J. Gordon, E.B. Zurif, AND D. LuCA, 1976 Right hemispheric damage and verbal problem solving behavior. Brain Lang 3:41-46.

Cave, K. R., And S.M., Kosslyn, 1989 Varieties of size-specific visual solution. J. Exp. Psychol. (Gen) 118:148-164.

Chananaschwili, M. M., 1984.

Neurosen Theorie und Experiment Akademie-Verlag, Berlin D.D.R. Pp. 566.

Charlot, V., N. Tozourio, M. Zilbovicius, B. MAZOYER, AND M. DENIS, 1992. ifferent mental imagery abilities result in different regional cerebral blood flow activation pattern during cognitive task. Neuropsychologia 30:565-580.

De Renzi, E., And H. Spinnler, 1967. Impaired performance on color task in patients with hemispherie lessions. Cortex 3 : 194-217.

De Valois, R. L., I. Abramov, and W.R. MEAD, 1967. Single cell analysis of wavelength discrimination at the lateral 
geniculate nucleus in the macaque. J. Neurophysiol. 30: 415-433.

DReWE, E. A., 1975. Go no go learning after frontal lobe lession in humans. Cortex 11: 8-16.

ENGELS, F. , (1873-1883) $1975 . \quad$ ialektik der Natur. Marx Engels Werke Band 20. Dietz Verlag, Berlin. pp 307-470.

EsPINOZA VARAS, B. 1971. Reflejo de enfoque y su inhibición: análisis de su integración neural. Disertación, Santiago-Chile.

Espinoza, S., and G. Santibañez-H., 1965. Habituation of orienting (targeting) reflex an food deprivation in cats Arch. Biol. Med. Exp. 31: 141.

Evans, E.F., 1978. Place and time coding of intensity in the peripheral auditory system: some physiological pres and centras. Audiology 17:369-420.

\section{Feddersen-Petersen, D., 1987} Hundepsychologie. Kosmos Gessellschaft des Naturfreunde. Franck`sche Verlag Landlung Stutgart. Pp. 104.

Fuster, J. M., 1973. Unit activity in prefrontal cortex during delayed-response performance: neuronal correlates of transient memory. J. Neurophysiol. 36:61-78.

FusteR, J. M., 1989. The prefrontal cortex: anatomy, physiology, and neuropsychology of the frontal lobe. New York: Raven.

FUSTER, J.M., 1990 Infero-temporal units in selective visual atention and short term memory. J. Neurophysiol. 64: 681-697.

Ganz, L., H. V. B. HiRsch, AND S.B. Tieman 1972. The nature of perceptual deficits in visually deprived cats. Brain Research, 44:547-568.

GoldenberG, G., I. Podreka, M. Steiner, AND K. Willmes, 1987. Patterns of regional cerebral flow related to memorizing of high and low imagery words: an emission computer tomography study. Neuropsychologia 25:473-486.
Goldenberg, G., I. PodreKa, M. Steiner, AND K. Willmes, 1989 Regional cerebral blood flow patterns in visual imagery Neuropsychologia 27: 641-664.

GoldenberG, G., AND C. ARTNER, 1991.Visual Imagery and knowledge about visual appearance in patients with posterior cerebral artery lesions. Brain cognition 15:160-186.

GoldenberG, G., I. Podreka, M. Steiner, AND L. DeECKe, 1992 Regional cerebral blood flow pattern related to verification of low and high, imagery sentences. Neuropsychologia 30:581-586.

GómEZ J.C., 1996. Non human primate theories of (non-human primate) minds: some issues concerning the origin of mindreading. En P. Carrurthers and P.k. Smith, eds. Theories of theories of mind. Cambridge University Press, Cambridge. Pp. 390.

Goodall, J., 1986. The Chimpanzees of Gombe. Patterns of Behavior. The Belknap Press Harvard University Press. Cambridge, Massachusettsand and London, England Pp. 674.

Gross, C.G., 1992. Representation of visual stimuli in inferior temporal cortex. Proe Royal Soc. London, 335:3-10

HALFord, G. S.,1993. Children`s understanding: the development of mental models. Hillsdale, N. Y. Erlbaun.

HARRIS, C.S., $1980 . \quad$ Insight or out of sight. Two examples of perceptual plasticity in the human adult. En visual coding and adaptability, C.S. Harris, Ed. Hillsdale, N.Y. Erlbaun p. 95-149.

Hubel, D., ANd T.N. Wiesel, 1962. Receptive field, binocular interaction and functional architecture in the cat's visual contex. J. Physiol. (London) 160:106-154.

Hubel, D., and T.N. Wiesel, 1963. Receptive field of cells in striate cortex of very young, visually inexperienced kittens J. Neurophysiol. 26:994-1002. 
Hubel, D., AND T.N. Wiesel, 1977. Ferrier lecture: functional architecture of macaque monkey striate cortex Proc, R. Soc. London (Biol.) 198:1-59.

ILYENKOV, E. (1960) 1982. Dialectics of the abstract and the concrete in Marx`s Capital". Progress Publishers. English translation by Sergei Kuziakov. Chapter 3, Ascent from the abstract to the concrete on the formulation of the question. p. 1-9.

JablonKa, E., M. L. Lamb, AND E. Avital 1998. Lamarckian Mechanisms in darwinian evolution. Ecol. and Evol. 13:206-210.

JACOBSON, C.F., 1935. Fluctional frontal association area in primates Arch. Neurol. Psychiatry, 33:558-569.

JOHNSON-LAIRD, P.N., 1970. La perception and memory of sentences. En Lyons, J., ed.New Horizons in Linguistic. Harmondsworth, Middlesex England: Penguin Book, pp. 261-270

Johnson-LAird, P.N., 1983. Mental Models: towards a cognitive science of language inference and consciousness. Cambridge: Cambridge University Press.

Johnson-Laird, P.N., 1993. Human and machine thinking., Hillsdale, N.J.: Erebaun"

KIANG, N.Y.S., T. Watanabe, E.C. Thomas, AND L.F. CLARKE, 1965. Discharge pattern of single fibers in the cats acuditory nerve. Cambridge, Mas:MIT Press

KNIGHT, R.T., 1991. Evoked potential studies of atention capacity in human frontal lobes. En Levin, H.S., H.H. Einsenberg, and A.L. Boston, Ed. New York: Oxford University Press pp.139-155

KofKA, K., 1935. Principles of Gestalt psychology" New York (Harcourt)

KonORSKI, J., 1948. Conditioned reflexes and neuron organization. Cambridge University Press.

KONORSKI, J., 1967. Integrative activity of the brain. An interdisciplinary approach. The University of Chicago Press. Chicago and London.
Koref-Santibañez， S., and G., SANTiBAÑEZ-H., 1986. Specific and Individual adaptation. En Santibañez-H., G., y Lindemann, M. Eds. Introduction to the physiopathology of neurotic states. VEB George Thieme Leipzing. Pp. 357.

Koref-SANTiBAÑEZ, S., 1984. The present del state of behavior genetic analysis Biologisches Zentralblah 103:241-266.

KossLyn, S.M. 1980. Image and mind, Cambridge Mass Harvard University Press.

Kosslyn, S.M., R.A. FLynN, J.B. AMSTERDAM, AND G. WANG., 1990.

Component of hight-level vision: a cognitive, neuroscience analysis and accounts of neurological syncrones. Cognition 34:203277.

LAWICKA,W. 1979. Auditory targeting reflexes: their determining role in directional instrumental responding, Acta Neurobiol. Exper. 39:537-552.

Le Bihan, D., R. Turner, T.A. Zefriro, C.A. Cuenod, P. JeZZARD, AND V. BONNEROT, 1993. Activation of human primary visual cortex during visual recall: a magnetic resonance imaging study. Proc. Nat. Acad. Sci. USA.

LeVine, D. N., J. Warach, AND M.J. Farah, 1985. Two visual system in mental imagery: dissociation of "What and Where" in imagery disordies due to bilateral posterior cerebral lesions. Neurology 35:1010-1018.

LOWE, D.C. 1985. Perceptual organization and visual recognition. Boston: Kluver.

LYNCH, J.C. AND J.W. MC LAREN, 1989.

Deficits of visual attention and saccadic eye movement after lesions of parieto-occipital cortex in monkeys. J. Neurophysiol. 61:74-90.

Marais, E. (1925) 1989. The soul of the apes. The soul of white ant. Penguin Book Pp. 314.

MarX, K. (1845) 1969. Thesen über Fenerbach Marx Engels Werke Band 3, Dietz Verlag. Berlin. Pp. 7. 
MARX, K. (1857-1858) 1974. Grundrisse der Kritik der politischen Okonomie. Dietz Verlag. Berlin. p. 21-31

MARX, K. (1859) 1951. Zur Kritik der politischen Okonomie. Dietz Verlag. Berlín. Pp. 256-270.

Mc Donald, S., and R. Waler, 1986. An investigation of the ability to process inferences in language following right hemisphere brain damage. Brain Lang 29:68-80.

Mc Naughton, B.L., J.J. Knierin, and M.A. Wilson, 1995. Vector encoding and the vestibular foundations of spatial cognition: neurophysiological and computatioal mechanism, En. M.S. Gazzaniga, The cognitive neurosciences. A Bradford Book. The MIT Press, Cambridge, Mass, London, England p. 585-595.

Mountcastle, V.B., J.C. Lynch, A. Georgopoulos, H. SaKata, and C. Acuña. 1975. Posterior parietal association cortex of monkey: Command function for operating within in extrapersonal space. J. Neurophysiol. 38:871-908.

Movshon, J.A., E.H. Adelson, M.S. GizzI, AND W.T. Newsome, 1986 The analisis of moving. Experimental Brain Research, Suppl. 11:117-151.

MunFoRD, D., 1991 On the computational architecture of neocortex: The rol of the talamo-cortical loop, Biol. Cybern 65:135-145

Newsome, W.T., K.H Britten and J.A. Movshon, 1989. Neural. Correlate of a perceptual decision. Nature 341:52-54.

PAKARD, V. 1959. The status seakers. David McKay, Inc. New York. Pp. 385.

PaIvio, A., 1971. Imagery and verbal processes. New York: Holt, Rinchart, and Winston.

Pavlov, J. P., 1904. Sur la sécrétion psychique des glandes salivaire. Archives internationales de Physiologie 1: 119-135.

Pavlov, J.P. (1926), 1953. Vorlesungen uber die Arbeit des Grosshirn hemispharen. Samtliche Werke. Band IV. Academie Verlag, Berlín Pp. 183.

Pavlov, J.P., 1927. Conditioned reflexes an investigation of the physiological activity of the cerebral cortex. Translated and edited by G. V. Anrep. London: Oxford University Press.

Penfield, W., and T. Rasmussen, 1950 The cerebral cortex of man. Brain. 88:237-296

PolK, T.A., AND A. Newell, 1992. A verbal reasoning theory for categorial syllogisms. Mimeo Department of Computer Science. Carnegie Mellon University.

PoPPER, K. AND J. ECCLES, 1977. The self and its brain. Springer International Pp. 595.

PovinelLI, D. 1996. Chimpanzee theory of mind?, the long road to strong inference. En P. Carruthers and P.K. Smith, eds. Theories of theories, of mind. Cambridge University Press Cambridge Pp. 390.

RIPS, L. J., 1983. Cognitive processes in propositional reasoning. Psychol. Rev. 90:3071.

Robin, N., AND K.J., HolyoaK, 1995. Relational complexity and the functions of prefrontal cortex. In Gazzaniga, M.S. the cognitive neuroscience. A Bradford book. The MIT Press. Cambridge, Mass. London England p. 987.

SaAvedra, M.A., 1999. Principios de aprendizaje. Ed. Universitaria, Santiago Chile. Pp. 103

Santibañez-H., G. y H. H. Osorio, 1999, El objeto de la Psicología II. Revista de Psicología, Universidad de Chile, Vol. VIII. 7-29.

Santibañez-H., G. y H. H. Osorio, 1998, El objeto de la Psicología I. Revista de Psicología, Universidad de Chile, Vol. VII. 89-104.

Santibañez-H., G., 1986. P r i n c i p a 1 functions of the neuroendocrina system: the functional basis of the integrative activity of the brain. En Santibañez-H., G., y Lindemann, M., eds. Introduction to the 
physiopathology of the neurotic states. VEB Gerorg Thieme-Liepaig. Pp. 357.

Santibañez-H., G. 1990. Subjektivität als dritte umwelt. Deutsche Zeitschrift $f$. Philosophie 39:463-476.

SANTiBAÑEZ-H., G., 1997 En torno a la Universidad y la cultura, $¿$ Del terror a la servidumbre. LOM ediciones Pp. 315.

Santibañez-H., G., A. Carmona, and S. MidDLETON, 1966. Reactivity changes in the Central Nervous System concomitant with fear and food deprivation states. Acta Physiol. Latinoamer. 16:180-188.

Santibañez-H., G., AND H. Siegmund 1976. The targeting reflex. Acta Neurobiol. Exper. 36: 181-203.

Santibañez-H., G., and H. Siegmund, 1977. Die targeting reaktion. En 100 Jahre Physiologiches Institut. Humbolt University. Berlín Pp. 182-193

SHEPARD, R.N. 1978. The mental image. Am. Psychol. 33:125-137

SHERRINGTON, C.S. 1906. The integrative action of the nervous system. New York Charles Scribner`s Song. New York.

Siegmund, H., M. Stoppa, and G, SAntibañez-H., 1987. Eye and head movements to visual and auditory targets. Activitas Nervoso Superior 29:73-82.

Sechenov, J.M., 1965. Los reflejos del cerebro. Academia de Ciencias, Museo Histórico de las Ciencias Médicas Carlos J. Finlay. La Habana, Cuba. Pp.231.

SoKOLOv, E.N., 1958. Measuring the senusitivity and reactivity of the conditioned reflex in connection with the interrelation between orienting and defensive reactions. En L.G. Voronin, A. N. Leontiyev, A.R. Luria; E.N. Sokolov, and O.S. Vinogradora. Acad. Pedag. Nauka eds. RSFSR.

SoKOlov, E. N., 1963. Higher nervous functions: the orienting reflex. Annual Review of Physiology 25: 545-580.
Talbot, W.H., I. DaRian-SMiH, H.H. Kornhuber, and V.B. Mountcastle, 1968. The sense of flutter-vibration: comparison of the human capacity with response patterns of mechanoreceptive afferents from monkey hand. J. Neurophysiol. 31: 301-334.

TIERNEY, A.J. 1986. The evolution of learned and innate behavior: Contributions from genetics and neurobiology to a theory of behavioral evolution. Annimal Learn. and Behav. 14:339-348.

Treisman, A.M., 1969. Strategies and model of selective attention Psychol. Rev. 76:282-299.

Vallbo, A.B., 1995. Single afferent neurons and somatic sensation in humans. En Gazzaniga, M.S. ed. The cognitive neurosciences. A Bradford Book, the MIT Press. Cambridge, Massachusetts, London England.

WADDINGTON, C.H. 1975. The evolution of an evolutionist. Edinburgh, University Press Pp. 429

Wagman, I. H., 1964. Eye movement induced by electrical stimulation of the cerebrum in monkeys and their relationship to bodily movements. En M.B., Bender, eds. New York: Harper and Rows, p. 18-39.

ZeKE, S., AND S., SHIPP, 1988. $\mathrm{T} h \mathrm{~h}$ functional logic of the cortical connections. Nature 335:311-317.

ZERNICKI, B., 1991. Visual discrimination learning in binocularly deprived cats: 20 years of studies in the Nencki Institute. Brain Research Reviews 16:231-236.

ZeRNICKI, B., 1993. L e a r n i n g deficit in lab-reared cats. Acta Neurobiol. Exper., 53:563-567.

ZIPSER, D., AND R.A., ANDERSEN, 1988. A back propagation programmed network, that stimulates responses properties of a subtest of posterior parietal neurona. Nature 331:679-684. 
